DIscLssion

Dr. Cuamles Fre, lialadelphia: I have not given up entirely the use of milk in the feeding of ehildren with typhojd fever, thongh its use may be carried to such an extent as to be harmful. One sliould not draw any general conclusions but slould study more elosely the digestive powers of the child. Skimmed milk has a place in the treatment of typhoid fever. It helps the proteid content in food, a fact that should be kept in mind. skimmed milk should be used more than once " lny.

Dr. Wamken Colmanas: I assume that the metabolism renctions in a child with typhoid fever are the same as in the alult. I have been using a diet, the main object of which is to supply the patient with an nmount of food sufficient to cover the amount of energy lost. In Bellevue and the Allied llospitals, during the years 1008 , 1909, and 1010, there liave been 875 enses of typhoid fever and 137 dentlis. During this period there have been 102 patients on a high euloric diet with eleven deatlis. Among the 773 patients not on the high ealoric diet, there were 126 deaths, or 10.8 per eent. mortality for the first class, and 16.3 per cent. for the seeond. The use of the lighi caloric diet has been followed by the subsidence of the diarrhea with which the patient entered the hospital. In those cases in Which hemorrhage has occurred, the loss of blood was slight. We have lost but one patient from liemorrlage. With a high caloric diet convalescence is much shorter.

DR. AugusT SwHiser: For twenty-two years I have not used milk in the trentment of typhoid fover. Diarrhen, intestinal disturbances and toxemia are increased when milk is given. I would emphasize the inportance of thoroughly cleansing the alimentary tract: the bowels slould be washed ont every day.

\section{IDAHO STATE MEDICAL ASSOCIATION}

Ninete'nth Annual afceting, held at Botsc, Oct. 11-13, 19J1

The President, Dr. JoinN W. Givens, Orolino, in the Chnir

\section{Officers Elected}

A list of the oflicers elected was published in THe JounNaL, October 14, p. 1464.

\section{Medical Inspection of Schools}

Dr. Geonoe E. Hyde, Rexburg: Seventy-six thousand children attended Idaho public schools last year, yet very little has been attempted in the way of medical inspection. An effort is being made to provide suitable buildings and appara'tuis for the pupils and improve the sanitary condition. of the buildinge and grounds, but prnctically nothing more has been done. The public school system of Idaho cost the state $\$ 2,575,506,10$ last: year, and, th it has been carefully estimated that 20 per cent. of the amount puid for the education of chi]dren in public schools is spent to enable bnckward children to repeat grades, Idalio is, therefore, probably spending over $\$ 500,000$ yearly on backward children, most of whom are suffering from removable defects.

Careful and systematic examination of 400 selool clildren gave the following results, which compare quite favorably With like statistics from eastern towns and cities, Of these 10 had deafness in some degree; 8 had adenoids; 54 had hypertroplied tonsils; 58 had mild defects of vision; 41 had defects of vision from $20 / 50$ to $6 / 200 ; 31$ had headache after rending; 12 had to change position to see to write their lessons; 1) could not see writing on blackboard from where they sat; 240 had defective teeth, one-fourth of these very bad; 5 had mitral regurgitation, with a history of rheumatiom in $4 ; 112$ 8howed no discoverable defects.

\section{Discussion}

DR. J. M. TAYLOR: To bring about medieal inspection it is necessary to educate the people, and to accomplish this, thorough and easily understood demonstrations must be made to the public by the health authorities. An excellent argument is to show the parents low the cost of educating their children can be decreased by the discovery and removal of physical defects, and improving the sanitury enviromments surrounding their clitidren.
Dr. August C. Bente, Salt Lake City: Medical inspection of schools is necessary; the question is, How can it be best bronglit about? Medical inspection should be under the control of the bourd of health, and health ollicers should have more authority. It is economy to conserve the health of our children. Defective children should not be seen in our schools, for one backward child takes as much of the teacher's time as twenty normal chiłdren; hence these defectives are a constant source of additional expense to the public.

\section{The Importance of Intestinal Rest in Dealing with Acute Intestinal Conditions}

Dr. C. N. SuTresek, Walla Walla, Wash.: First should be considered psychologic rest, the avoidance of all things that may tend to excite the pritient and the encouragement of contidence in the patient and the belief that he is going to get well. Second comes mechanieal rest-complete relaxation of atl muscles, with supports under knees and back. Third may be considered physiologic rest. Do not feed these patients. A little chewing-gum or good chocolate candy will sutisfy and keep them busy. Upiates are seldom necessary. A hypodermic of sterile water will usually act just as satis. factorily. Fourth comes surgical rest. This is brought about by the use of a proper surgical bed, a comfortable operating table, with warm aseptic cushions or pillows for propping patient.

\section{Discussion on Therapeutic Paeumothorax}

1)k. C. N. SUtreser, Walla Walla, Wash,: A patient of mine, who gave the clinieal picture of pulmonary tuberculosis, secured the eflect of compression of the lung by lying on one side for four and one-hinlf months, but later developed an empyema which lad to be drained; the patient recovered entirely.

Dk. A. C. Benle, Salt Lake City: Nitrogen gas is better than air because it is more slowly absorbed. The Röntgen ray should alway's be used in connection with this treatment to better control the amount of compression.

DR. C. S. Whrre, Portland, Ore.: Every case of tuberculosis should be sent to a sanatorium for at least a month or two for the education such stay gives. Every patient goes home as a missionary teacher of good hygiene; he not only learns how to take care of himself, but he has become watchful of others and can and will advise and instruct his family and friends.

D1R: R. C. Marson, Portland, Ore.: It is quite important to go thoroughly into the patient's personal and family history. 'l'he time and place of infection can of ten be determined. It is important also to inquire into the history of the homethe house or houses in which he has lived. In going into the personal history, remember that some previous illness diagrosed as typhoid, iheumatism or an atypienl pneumonia, may in reality have been a tuberculous infection.

\section{Discussion on Treatment of Tuberculosis}

Dr. L. P. McCalla, Boise: Every stute should have a sanatorium for the trentment of tuberculosis. It is the duty of this and every state to provide a suitable institution for that pupose. I have abandoned the use of tuberculin as a therapentic measure, and only occasionally use it for diagnostic purposes. Climate has a beneficial preventive eflect. Germs do. not grow us well in Colorado or Idaho as they do in a low, moist, warm climate. Giving greater care to food and its preparation is important. The ideal kitchen should be a laboratory, presided over by an intelligent and well-trained and well-paid person.

DR. J. W. Givens, Orofino: In reference to the relation climate bears to tuberculosis, I know from personal experience and knowledge that tuberculous patients form a greater proportion of admissions to the Oregon Asylum than they do to those in the Idaho insane institutions. Fewer cases develop in a dry climate than in the moist. The question what and how to feed these patients is all-important. The profession differs as to this, so they often fail to give proper advice to their patients. We know how to feed a cow to accomplish certain ends, but we do not understund yet the best method of feeding humun beings, especially sick ones. 


\section{Discussion on the Pituitary Body}

1)r. Wilson Jonsston, Seattle, Wash.: We know that the secretions of the pituitary boly and other ductless ghands are absolutely essential to the development of normal men and women. 'The relution of the pituitary body to the lyyperplasiu of pregnancy in women and numals, regulating tho type of body developed, is very interesting. Jinlargement of the ovary may be a local manifestation of begimuing acro. mogaly due to disease of this body. From a surgieal stand. point our incerensing knowledge of the functions of this and other allied glands menns that we must make more careful and better diagnoses.

Dh. Fonnk Hingan, Spokane, Wash., This subject is of more importance to the internist and greneral practitioner that to the surgeon. Surgicul operation on the pituitary body is very diffeult for even expert surgeons, and is dangerous to the patient, so we must look to the internist for a specifie ramedy. We now lave a sperific for myxelema, and the prospeets are favorable for a specifie for disense of pituitary body.

\section{Youth and the Sex Problem}

])k. W. T. Widinamsox, l'ortland, Ore.: Children have a right to expect their parents to inform them concerning their sexunl functions and the part sex plays in the scheme of life and procreation of our kind. It is impossible for chisdren to develop to full adult life withont acquiring this knowledge, and it is far better to lanve this information properly given them by responsible persons whom the child has been tanght to respect and love, than to lave the child accuire this knowledge from improper persons under unfavorable conditions. It is our duty as parents to protect the young from the evil influences of others and from their own jgnorance. Many boys and girls are vietims of disenses and inmoral practices because of their luck of knowledge on this subject, and the great question is. how shall we educate our elislden? A society has recently been organized in Portland for the purpose of discussing thits problem and carrying on a (ampaign of education among the people. As the parents bave apparently manifested no interest in this subject, it is proposed that the physicinns lend their aid in instructing the parents and tenchers low best to reach the children. In the schools it ought to be easy to begin this study early in the child's school life by unfolding to him or her the first life plan of plants and the lower animals, and in a graduil mamer explain and lead up to procrention and the relution the sexes benr to Nuture's selieme of lifo.

Several social conditions exist which tend to further the evil consequences of this lack of knowledge of the sex question. Especinlly in the larger cities, many young girls work in department stores, shops and offices. Most of them are underpaid, yet expected to appear neat and well dressed, and many of these go wrong, first, through ignornnce, and then because the leading of such immoral life enables them to lrave nicer clothes and get more enjoyment from their leisure lours. Then, too, many boys and girls are allowed to roam the streets at night. Wnforcement of the curfew ordinunce would in a great monsure remove this source of temptation. Jndiscriminate dancing is a third social condition found in all lurge towns and cities. Young men, and especially young women and girls, should not be allowed to attend public dances, where they ure upt to meet undesirable acquaintunces, without proper escort.

It is proposed to correct all these undesirable conditions so far us possible by education of the people. Ignorance is also undoubtedly to blame for a great deal of the sexual disenses. afflicting men and women. Most of the operations done on womon for pelvic disease are due to venereal disease. This is not surprising when wo consider that probably 75 per cent. of men have been infected with gonorrhea in eurly life; and that from 5 to 18 per cent. of men have suffered from syphilis. Now, most all of these infections are the result of ignorance and may be traced to improper sexual relutions, though it is not impossible to become infected without intercourse. So we are all in more or less danger from the general prevalence of these diseases.

\section{Current Medical Literature}

\section{AMERICAN}

Titles marked with an asterisk (*) nre abstracted below.

Northwest Medicine, Seattle, Wash.

November, 111, No. 11, $p 1$. 308-331,

1 "Some Causes nnd lieverithon of Insanlty and Feeble-Minded-

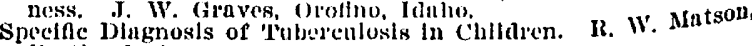
l'ortland, ore.

Silould a 'ruberculous Mother Nurse llor Child? M. NacLachling, l'ortland, Ore.

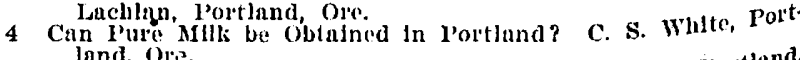

Intestinal Diseruses in Infants. J. Ib. Iilderback, portland.

Ore.
(3) Modification of Cow's Milk. F. J. Labbe, Portland, Ore.

7 * Treatment of Choren. W. T. Willinmson, l'ortlund,

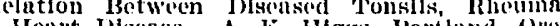
Ifenrt Disense. A. K. Higgs, Portlund, Ore, if

Differential Dlagnosis Between the Exinthem Dammisch, J'ortland, Ore.

10 * Cure of listula in $A$ no without injury to Sphincters. K. A. J. Mackenzle, Dortland, Ore.

1. Insanity and Feeble-Mindedness.-To prevent feeble-mindedness and insanity, Givens says, every child should be born of reasonably healthy parents. Every person should liave the necessary elements of gool intrition, purticularly an abundance of pure air, good water and proper food. All toxic sub stances from outside the body should be excluded so far as possible and all products of body waste should be regularly eliminated. Such habits of exercise of body and mind, rest and sleep, should be tanght and observed as will tend to pro duce and maintain at sound mind in a sound body.

7. Treatment of Chorea.-The trentment recommended by Williamson consists of rest, nutrition, elimination and drug to combat the symptoms.

8. Diseased Tonsils, Rheumatic Fever and Heart Disease.The relation between tonsillar inflammation and acute rhe matism has been almost universully neknowledged by clinicians for several years, but it is only of late that it las been pointed out that there is a relation between tonsillitis and various lesions of the heart. Observers difler as to the percentage and as to certain details of rheumatic and heart complications following tonsillitis, but us a general proposition all are prac tically agreed that there is a relation between them. Although a specific etiologic factor lins not been isolated, it is generally agreed that acute rheumatism proper is a specific infectious disease of uniform etiology and that the tonsil is ofton the portal of entry not only for the articulur infection but also for myocardial infection. The oflending tonsils are not necesparily arge; in fact they are often small and submerged so that they may be overlooked entirely as a causntive factor in that they may be overlooked entirely as a causative factor in any systemic affection. Higgs says that the patient be cntitled to protection from tonsillar infection if it can be done without seriously jeopardizing life. Internal medication, cleaning out the crypts and local applications relieve the local inflammatory symptoms in certain cases and some cases may be practically cured by such treatment, but in most cases such measures are-wholly ineflicient either to relieve immediate symptoms or to ward off future attucks and in such cases on slould resort to some surgical procedure.

10. Abstracted in The Jounnal, Aug. 5, 1911, p. 505.

Journal of Cutaneous Diseases, New York

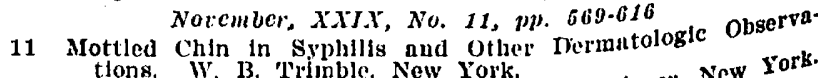
thons. W. 13. 'Irinble, New York.

12 Erythema Nodosum Syphllitfeum. F. J. levlseur, New

13 I'atal Case of Blastomycosis. F. J. Sheplerd, Montrea

\section{Interstate Medical Journal, St. Loui}

Nonember, XVJII, No. 11, pp. 1073-1160

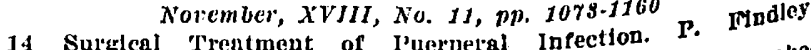

14 Surglcal Trentment of l'uerpelal infection. T. Indey

15. Modern , Nend of Isychlatiy. J. V. May, FIshkill-on-lbe

16 Atypleal Mrastolditis. I. B. Dench, New York. Used to pete'

17 Chronic Relapsing Gonorrhea aud Method

18 Nine Its Cure. C. M. Whitney, Boston. Wonsil Operations C. 4 . Gundelach, st. Louls. 